\title{
Subjectivism and Relational Good
}

\author{
Fritz-Anton Fritzson ${ }^{1,2}$ (D)
}

Accepted: 29 March 2018 / Published online: 9 April 2018

(C) The Author(s) 2018

\begin{abstract}
In this paper, a distinctly subjectivist analysis of the nature of relational goodness or goodness for is proposed. Like the generic subjectivist analysis of value, the proposal is to analyse value in terms of attitudes. Specifically, the proposed analysis of goodness for appeals to a special kind of attitude: namely, so-called for-someone'ssake attitudes. Unlike other analyses in the literature that have appealed to this kind of attitude, the analysis proposed here is not a fitting-attitude analysis. Rather than appealing to for-someone's-sake attitudes that it is fitting to have or that there are reasons to have, the proposed analysis takes actually held for-someone's-sake attitudes to ground or constitute goodness for (relative to the subject who holds the attitude). The analysis should be attractive to those already within the subjectivist camp. One of its appeals is that it is a special case of a general subjectivist approach to values, thus showing that subjectivism provides the resources to analyse relational values.
\end{abstract}

Keywords Good and good for · Relational value · Personal value · Value subjectivism · Constitutive ground of value $\cdot$ Good relative to

\section{Introduction}

In her paper 'Objectivism and Relational Good', Connie S. Rosati observes that 'making sense of good for will be important to vindicating a plausible objectivism' (2008: 318). ${ }^{1}$ The present paper begins from the conviction that making sense of good for is no less important for a plausible subjectivism. While at least one author has offered an analysis

\footnotetext{
${ }^{1}$ Rosati makes the importance of making sense of good for conditional on the conjecture that 'objectivism or realism about ethics is true'; that 'normative facts exist' (318). I will be labouring under the opposite conjecture that subjectivism and non-realism are true (it need not be assumed, however, that all objectivists are realists and that all non-realists are subjectivists).
}

Fritz-Anton Fritzson

fritz-anton.fritzson@fil.lu.se

1 Department of Philosophy, Lund University, Helgonavägen 3, 22100 Lund, Sweden

2 IFILNOVA Institute of Philosophy, New University of Lisbon, Lisbon, Portugal 
of goodness for, or personal value, that is neutral between subjectivism and objectivism (Rønnow-Rasmussen 2011), ${ }^{2}$ most philosophers who have written about goodness for have done so within an objectivist framework (e.g. Hurka 1987; Thomson 1997; Regan 2004; Rosati 2008; Zimmerman 2009; Kraut 2011). ${ }^{3}$ Rosati is explicitly aimed at an objectivist understanding of relational goodness, and other authors on the topic have implicitly relied on objectivist assumptions. ${ }^{4}$ I offer a distinctly subjectivist analysis of what it is for something to be good for someone. Like the generic subjectivist analysis of value, which has been developed elsewhere, the proposal here is to analyse value in terms of attitudes. Specifically, the attitudes appealed to in the proposed analysis of goodness for are so-called for-someone's-sake attitudes. This is something that the subjectivist analysis shares with some other analyses in the literature, but unlike these other analyses the present one is not a fitting-attitude analysis. Rather than appealing to for-someone's-sake attitudes that it is fitting to have or that there are reasons to have, the analysis proposed here takes actually held for-someone's-sake attitudes to ground or constitute goodness for relative to the subject who holds the attitude. In short, something being good for someone is understood in terms of it being actually favoured for that someone's sake by some subject (who may or may not be identical to the person for whom something is good). The ensuing personal values, like all values, are seen by the subjectivist as relative to the perspectives of favouring subjects.

Before presenting the subjectivist analysis of goodness for in Section 4, some preliminary work needs to be done in pinning down what is going to be analysed (Section 2) and also to briefly rehearse the generic value subjectivist thesis (Section 3). The fifth and final main section of the paper (before the brief concluding note) addresses some concerns and objections against the analysis along with some suggestions on how they might be resolved.

\section{2 'Good For', the Very Notion}

The notion of 'good for' - as distinct from the notion of 'good' (period) - has been a subject of growing interest among philosophers in recent years (e.g. Rosati 2006, 2008, 2009; Rønnow-Rasmussen 2007, 2011; Zimmerman 2009; Kraut 2011; Korsgaard 2013, 2014). Goodness for is an example of a relational value (typically a value in relation to a person and is therefore sometimes called 'personal value, ${ }^{5}$ )

\footnotetext{
2 Though Rønnow-Rasmussen is ultimately inclined to reject subjectivism (2011: 17).

${ }^{3}$ The claim that most writers on good for are objectivists could be contested by drawing attention to the fact that many philosophers writing about 'well-being' or 'welfare' relate these notions to desires or other subjective states. While this is true, as will become clear later on, not all views that relate value to some subjective state are forms of subjectivism as I understand it. Much of the literature on well-being is concerned with substantive, first order views on what is good for people, and subjectivism and objectivism will here be understood as second order views about the nature of value. Furthermore, as will also become clear below, I do not think that wellbeing and goodness for are synonymous.

${ }^{4}$ An exception is David Gauthier who defends an explicitly subjectivist (and relativist) view of value similar to mine. However, beyond recognising that 'it is possible to distinguish what is good for some person from what is straightforwardly good' (1986: 50), Gauthier does not say much on how he understands goodness for, and he does not provide an analysis thereof.

5 I will talk about 'relational value' rather than 'personal value' because I see the latter as being a sub-class of the former, and my proposal is not restricted to analysing what it is for something to be good (or bad) specifically for persons. I wish to leave open the issue of for what kinds of beings things can be good or bad. For a subjectivist, this matter ultimately hinges on which kinds of beings figure in our attitudes in a particular way that will be specified below.
} 
and can be contrasted with straightforward goodness, which is a non-relational value. ${ }^{6}$ A thing to note is that not every use of the words 'good for' (in a sentence of the form ' $x$ is good for $a$ ') is an ascription of a relational value (or of any kind of value). Sometimes, ' $x$ is good for $a$ ' is used to mean merely that ' $a$ likes (or enjoys, appreciates, etc.) $x$ ', or ' $a$ thinks (believes, judges, etc.) that $x$ is good' (better called 'good according to'), or ' $x$ advances some goal that $a$ has (or is assumed to have)' or something along these lines. ${ }^{7}$ Such uses of 'good for' do not seem to me to ascribe values, and I will set these uses aside for the purposes of this paper. What I am interested in is the nature of the values that are being ascribed by those uses of 'good for' that do ascribe values (assuming that there are such uses). ${ }^{8}$

Some authors have treated 'good for' as synonymous with 'well-being', while others have resisted such identification. Rønnow-Rasmussen has argued for the conceptual distinctness of 'good for' and 'well-being' along the following lines. While 'good for' is a thin value notion and 'well-being' a thick one (or perhaps not even a genuine value notion at $\mathrm{all}^{9}$ ), they can hardly be synonymous (2011: 106-107). Even if we would agree with Michael Smith that 'All ethical concepts, even the maximally thin ones, turn out to be a little bit thick' (2013: 98), this would not undermine Rønnow-Rasmussen's point because even if 'good for' is a 'little bit thick', 'wellbeing' is still thinker, so the claim that they are synonymous remains dubious. My own suspicion is that a conceptual analysis of 'good for' would indeed yield a different result than would such an analysis of 'well-being'. ${ }^{10}$ It may of course be insisted that the only thing that is good for people is that their well-being is

\footnotetext{
${ }^{6}$ As pointed out by Richard Kraut, various Latin and French phrases have been used to denote what I call nonrelational goodness, such as simpliciter, tout court or sans phrase (2011: 5). Different authors have chosen different contrasts for 'good for', including 'simply good' (Moore 1993/1993), 'straightforwardly good' (Gauthier 1986), and 'good period' (Rønnow-Rasmussen 2007, 2011). Which term to use is a matter of taste. I would however object to using the term 'absolute' (as Moore and Kraut also did) to denote non-relational values because I take absolute to contrast not with 'relational' but with 'relative', and as I have argued elsewhere (Fritzson 2016), these are not the same. Keeping relational and relative separate is of vital importance also to my project in this paper.

${ }^{7}$ Hurka gives examples similar to those I have given here. He observes that claims such as these are descriptive rather than evaluative or normative (1987: 72-73). Cf. Rønnow-Rasmussen (2011: 96-107).

${ }^{8}$ Cf. Rosati (2009). Rosati is right to criticise the view "that "good for" expresses a single relation across uses' (215). But I think that she goes too far when she concludes that there are several distinct normative good for relations. If we leave aside those uses of 'good for' that do not ascribe values (and that are not normative), I think we can maintain that there is a single normative good for relation. However, depending on the relata in a particular case (as well as on the specific properties in virtue of which something is good for someone or for something), we get different relational values. For example, if the entity for whom something is good is a person, the value in question may be called a 'personal' value. So, the multiplicity of relational values can, I believe, be respected without introducing more than one good for relation. This claim would require further argument, but I will not pursue that here.

${ }^{9}$ Rønnow-Rasmussen acknowledges the possibility (only to set it aside) that 'welfare' may not be an evaluative notion at all, but a purely descriptive notion open to a naturalistic analysis (106). Note that if welfare/well-being is thus understood, this leaves open the question of whether welfare/well-being is good for people.

${ }^{10}$ As per Rønnow-Rasmussen's (2007) concession, there may well be a sense of 'good for' - what we may call the 'welfare sense of good for' - in which ' $x$ is good for $a$ ' is taken to mean the same as (or something similar to) ' $x$ enhances $a$ 's well-being'. But this is not the only sense of 'good for', and like Rønnow-Rasmussen's analysis of personal value, mine too is not restricted to the values picked out by the welfare sense of 'good for'. RønnowRasmussen writes about his own analysis of personal value that it 'captures a central sense of value-for', adding that 'However, I cannot eliminate the possibility that "value for" is ambiguous' (424). I believe that my own analysis captures the same sense of 'good for' (or rather, the values that are thus picked out) as that of RønnowRasmussen, but within an explicitly subjectivist framework.
} 
enhanced. But that, I believe, is not something that is built into the meanings of the terms, or that can be revealed by an analysis of the concepts, but would require taking a substantive normative stance about what is good for people. I prefer to treat well-being as just one of many different things that can be good for someone (cf. Rønnow-Rasmussen 2011: 106). From here on, I shall focus on goodness for (rather than on well-being), which I take to be normatively more interesting. However, the difference between goodness for and well-being will become relevant in responding to one of the objections to my analysis in Section 5.

\section{Subjectivism in Value Theory}

Since I have developed and discussed the generic value subjectivist view at length elsewhere (Fritzson 2014), it is only necessary here to briefly rehearse the general features of this view. Subjectivism and objectivism are here seen as rival second order views about the nature of value. There need be no disagreement between a subjectivist and an objectivist concerning what is valuable or in virtue of which of its features it has its value. I take it that it is common ground among subjectivist and objectivist value theorists that value is something that accrues to objects ('value bearers') and that it depends ('supervenes') on the non-evaluative features of these objects. What is distinctive about subjectivism is the thesis that whatever value an object has, this value is bestowed upon it by some attitude that some subject has towards the object in question. Values are thus seen as being conferred upon otherwise valueless objects by the attitudes that we have towards the objects in question. Wlodek Rabinowicz (in Rabinowicz and Österberg 1996) puts it like this:

[Values] of states of affairs are in a sense created by something external — by our ... preferences, but they do not supervene upon the preferences. Instead, they supervene on those ... properties of the states of affairs for which the states in question are being ... preferred $(20-21){ }^{11}$

Rabinowicz introduced the technical notion of 'constitutive ground', and insisted on the need to distinguish between the features on which value supervenes and the features that are constitutive grounds of value. Values are 'constituted' by preferences, and this is a claim about the ground of value and should not be confused with any claim about supervenience bases.

This view has since been further developed. ${ }^{12}$ Later formulations focus on pro and con-attitudes more generally, rather than narrowly on preferences. The type of attitude involved determines the type of value in each case. An object is taken to be of (positive) final value insofar as it is favoured for its own sake; of (positive) instrumental value insofar as it is favoured for the sake of its effects. 'Favouring' functions as a placeholder for a wide range of different pro-attitudes (such as desire, admiration, cherishing, love, etc.), while 'disfavouring' for con-attitudes (such as aversion, hate,

\footnotetext{
${ }^{11}$ Rabinowicz and Österberg discuss this view (that I call subjectivism) under the name of 'the object interpretation' (of preferentialism). According to this view, value is ascribed to the objects of our preferences rather than to the satisfaction of preferences. Cf. Gauthier (1986).

${ }^{12}$ See, for example, Rabinowicz and Rønnow-Rasmussen (2000), Rønnow-Rasmussen (2003, 2011), and Fritzson (2014).
} 
etc.), which are taken to give rise to negative values. ${ }^{13}$ Another difference from the original account is that not only states of affairs but also objects belonging to other ontological categories (for example, concrete objects and persons) are admitted among our possible value bearers.

It may be objected that there is no need to introduce the novel concept of constitutive grounds as the subjectivist could just accept that the attitudes that are thought to constitute value are really themselves part of the supervenience bases. But the subjectivist should decline this invitation to bake attitudes into the supervenience base. Firstly, doing so would lead to an overly restrictive view about which objects can carry value; only states of affairs involving some subject having an attitude towards something. Secondly, and more importantly, such states would have their values regardless of whether they are objects of attitudes. Asking subjectivists to accept that would be asking them to acknowledge objective values! Hence, not allowing the subjectivist to draw the distinction between constitutive grounds and supervenience base would beg important questions against the subjectivist.

\section{Subjectivism and Goodness For}

The subjectivist analysis of relational value is an extension of the generic subjectivist analysis just outlined. While, in the generic view, values are seen as being grounded on attitudes, relational values in particular should be understood as being grounded on a special type of attitude: so-called for-someone's-sake attitudes. The general idea is that something is good for someone by being favoured for that someone's sake. The goodness for someone, $a$, of some object, $o$, (the relational value of $o$ for $a$ ) is thus grounded on some favourable attitude held towards $o$ for $a$ 's sake. For example, the event of Elisabeth winning a particular competition is good for her insofar as it is being favoured for her sake. Put in terms of the distinction between constitutive ground and supervenience base, the constitutive ground of a relational value is a for-someone's-sake attitude, and the supervenience base of the value are those properties of the valuable object (of the value bearer) for which it is being favoured for someone's sake. Like in the generic subjectivist analysis of value, 'favouring' (and 'disfavouring') function as placeholders for a range of different pro (and con) attitudes. However, it may well be the case that there are specific attitudes that, by their very nature, cannot be held in the for-someone's-sake mode. Take admiration, for example; it would be odd to admire something for someone else's (or for one's own) sake.

Like with non-relational values, relational values too may come in final and instrumental varieties. Elisabeth's victory may be favoured (for her sake) for the sake of its effects-for

\footnotetext{
${ }^{13}$ That the value of an object is conferred by something external to the object itself might seem to lead us to the conclusion that subjectivists cannot recognise values that are intrinsic. This worry is expressed by Shelley Kagan (1998). He correctly observes that 'the subjectivist does believe that many objects do indeed possess value as an end' (or for its own sake, what I here call final value). But Kagan goes on to say that 'Obviously, however, they do not possess that value solely in virtue of their intrinsic properties. For it is not an intrinsic property of an object that it is valued by some creature' (281). However, as pointed out by Rabinowicz and Rønnow-Rasmussen (2000), this conclusion depends on a conflation of the constitutive ground with the supervenience base. It is only the features of the valuable object in virtue of which it has its value that need to be internal to the object in order for the value to be intrinsic. On subjectivism, then, something is intrinsically valuable when the features of the object for which it is being favoured are all internal to the object. What Kagan fails to appreciate is that there is no need to give up, or rethink, the traditional understanding of intrinsic value in order to allow for talk of intrinsic value under subjectivism.
} 
example, for the sake of furthering her racing career - in which case, winning is instrumentally good for Elisabeth. If, however, winning the competition is favoured for its own sake (for Elisabeth's sake) it is finally good for her. ${ }^{14}$

What is it to favour something for someone's sake? Michael Zimmerman and Jonas Olson have expressed misgivings about this type of attitude. Even though he does not want to deny that we sometimes say things like 'I am pleased for your sake', Zimmerman claims that it is not clear to him what such expressions are supposed to mean (2009: 437). According to Rønnow-Rasmussen, favouring something for someone's sake can be understood as favouring it 'with an eye to' that someone (2011: 56). Put in these terms, when I wish, for Elisabeth's sake, that she wins the competition, I favour her victory with an eye to Elisabeth. Olson concedes that this answer is suggestive (2014: 347), but one might still insist that it remains unclear what it is to favour (or disfavour) something for someone's sake, or with an eye to someone, and to demand that proponents of value analyses who appeal to this peculiar attitude would say something more informative about its nature. Such a demand may be reasonable, but I cannot satisfy it here. A related worry is that there is no way to understand what it is to favour something for someone's sake other than in terms of favouring it for the sake of the good of that person. If that is so, it obviously will not do as an analysis of the good for that person. What we need is a characterisation of favouring for the sake of someone that is independent of value. ${ }^{15}$ Insofar as these worries are considered serious, it is a problem for any theorist who appeals to this kind of attitude; subjectivists being no worse off than others in this respect. If the reader shares the misgivings about forsomeone's-sake attitudes, I kindly ask him or her to put these to one side and to bear with me as I elaborate further on the subjectivist analysis of goodness for.

The issue of for whom (what kind of being or entity for which) something can be good (or bad) is not settled by the analysis. If it is a person, as in the example of Elisabeth, the ensuing value would properly be called a 'personal' value. We may think of a personal value as one kind of relational value, leaving it open whether personal values exhaust relational values. It may be insisted that only persons can have a good in the relevant sense and that in all cases of something's being good for someone $a, a$ is necessarily a person. ${ }^{16}$ As previously noted, for a subjectivist, this matter ultimately hinges on which kinds of entities play the role of 'someone' in our for-someone's-sake attitudes, that is, for the sakes of which kinds of entities we favour or disfavour things. I believe that many people favour things for the sakes of groups, such as families, and for non-human animals. I, for example, wish for my cat's sake that he will live a

\footnotetext{
${ }^{14}$ On Rosati's view, goodness for is necessarily a kind of extrinsic rather than intrinsic value (343). As Rosati notes, an intrinsic value has traditionally been taken to depend on a thing's intrinsic properties. Pleasure or happiness is often given as examples of bearers of intrinsic value. Pleasure is thus taken to have its value in virtue of its internal properties alone, in virtue of how it is in itself. Now, if this is right, and I favour this pleasure for your sake in virtue of its internal properties alone, then, according to subjectivism, this pleasure is finally intrinsically good for you relative to me. As an example of an extrinsic relational value, recall my example above of me favouring for Elisabeth's sake that she wins the competition in virtue of it being the most prestigious competition in the game. Being the most prestigious competition in the game is not an internal property of the competition, so in this case, the relational value is an extrinsic one.

${ }^{15}$ I thank an anonymous reviewer for Ethical Theory and Moral Practice for raising this concern.

${ }^{16}$ Rosati (2008) insists that the being for whom something is good must itself be valuable (340) and that good for a person operates in such a way that it presupposes 'the ethical value of persons' (344). This is questioned by Rønnow-Rasmussen who interprets Rosati's claim as making good for into a derivative value, always deriving from the impersonal (non-relational) value of the person whose good it is, and he fails to see why this must be so (2011: 104-105). It is true that (as Rønnow-Rasmussen also concedes) we often do consider the persons for whose sakes we favour things to be themselves valuable, but it is with regard to the person, and not with regard to the value of the person, that we have these attitudes.
} 
long and healthy life. Some people probably favour things for the sakes of plants (and some perhaps even for inanimate objects?).

Another issue on which the analysis does not take a stand is which kinds of objects can be bearers of relational value. Other than events, as in the example of Elisabeth's victory, the bearers of goodness for could perhaps be facts, states of affairs, experiences, concrete objects, persons, and more. Rønnow-Rasmussen gives the example of a concrete object that has personal value for him: a poem that his daughter wrote to him when she was a child (2011: 1). ${ }^{17}$ A reduction manoeuvre may be tempting to the effect of what is good here is not the poem itself but the state of affairs in which the poem exists or some such thing. While Zimmerman argues that the attribution of value to concrete objects is 'eliminable in terms of, or at least reducible to, an attribution of final value to some states of the objects' (2001: 39), Rabinowicz and Rønnow-Rasmussen (2000) argue against such reduction manoeuvres. ${ }^{18}$ For a subjectivist, the value-bearer in a particular case is whatever is being the object of the relevant value-constituting attitude. If the object of the relevant attitude is the state of affairs that something exists, for instance, then it is this state that carries the value in question; if it is instead a concrete object such as a poem that is the object of the attitude, then that is what carries the value. It seems that the objects of the relevant attitudes include not only states of affairs but also concrete objects, persons, etc. The issue might depend on the kinds of attitudes in terms of which subjectivism is formulated. If subjectivism were formulated exclusively in terms of preferences (like in its original formulation), it would perhaps be natural to think of the objects of value as being restricted to states of affairs. ${ }^{19}$ Even though we often say things like 'I prefer an apple to a pear', which taken at face value sounds like a preference for one concrete object over another concrete object, such preferences can perhaps always be understood as being for the state of affairs in which I eat an apple over the state in which I eat a pear. Subjectivists who operate with a wider set of pro and con attitudes such as caring, adoration, cherishing, honouring, respect, love, etc. should also be willing to allow that value may accrue to objects belonging to several different ontological categories. After all, it sounds decidedly odd to admire or respect a state of affairs, for example. ${ }^{20}$

As with Rønnow-Rasmussen's fitting-attitude analysis of personal value, what is distinctive about relational values in contrast to non-relational values lies in the special type of attitude involved. Though unlike Rønnow-Rasmussen's view that 'what is typical about objects that are good for, or bad for, persons is that a for-someone'ssake attitude is called for' (2011: 55), the normative element of being called for (or merited, appropriate, or fitting, or being such that there are reasons for particular proresponses towards it) plays no role in my analysis. Instead, it is that a for-someone's-

\footnotetext{
${ }^{17}$ It is not obvious that a poem is a concrete object. However, in this case, it is the particular piece of paper on which the poem is written that is of personal value.

${ }^{18}$ As argued by Rabinowicz and Rønnow-Rasmussen (2000), those attempting such a reduction manoeuvre seem to put the cart before the horse: if the existence (or preservation) of a certain object is valuable, it is because the object itself is valuable, not the other way around. The value of the object is scarcely explicable in terms of the value of the state (43). Also, it seems quite possible to hold that a certain object is valuable while at the same time deny that the existence of this object is a valuable state (43-44). Finally, they call into question why we would even want to reduce the value of concrete objects to abstract states of affairs in the first place (44-49).

${ }^{19}$ Gauthier (1986) is a case in point. He does not explicitly endorse the view that states of affairs are the only carriers of value, but he characterises his subjectivist theory of value in terms of preferences for states of affairs.

${ }^{20}$ Zimmerman suggests that this may be due simply to an accident of language (2001: 43).
} 
sake attitude is actually held that grounds or confers a relational value. ${ }^{21}$ In light of the fact that many of the advantages of fitting-attitude analyses are due to the attitude element (which is shared by my analysis) and that the majority of the objections that have been raised against such views have targeted the normative element (that my analysis eschews), I think that not being a fitting-attitude analysis is in this respect an advantage of my analysis. ${ }^{22}$ However, even though it is an advantage in one respect, ejecting the normative element of the fitting-attitude analysis may of course also give rise to some misgivings of its own to which I will return below.

A question that has so far remained unanswered concerns whose attitudes that are taken to ground or constitute the relational value of $o$ for $a$. One possible answer would be that it is always $a$ 's own attitudes that play this role. I believe that this would be overly restrictive as it would allow only what we favour for our own sakes to ground goodness for ourselves. I think that we need to allow that goodness for $a$ can be constituted by someone other than $a$. This leads me to introduce into the analysis the subject, $s$, who holds the attitude in question (where $a$ and $s$ may, but need not, be identical). That it is the attitude of $s$ and not $a$ 's own attitudes that grounds the goodness for $a$ (except in those cases where $a$ and $s$ are identical) is, I believe, entirely as it should be. This does not mean, however, that $a$ 's attitudes are irrelevant to what is good for $a$. The latter's attitudes enter into the picture whenever $s$ 's attitude is sensitive to $a$ 's attitudes, which may or may not be the case. Modifying the example of Elisabeth, we can imagine that my desire for her victory is conditional on her desire to win. In this case, if I was informed that Elisabeth in fact could not care less about winning the competition, my attitude would change. ${ }^{23}$ Only when what I wish for her sake is that she wins the competition regardless of what she wants, would winning the competition be good for Elisabeth (relative to me) even if she herself did not care about winning. In the latter case, no information about what Elisabeth wants would change my attitude.

That values are always relative to individual subjects is an important implication of my proposed analysis. This implication is not unique to the subjectivist's understanding of relational values in particular but holds for values in general according to the subjectivist. The relativistic implication can be made explicit in the following way:

An object, $o$, is good for someone, $a$, relative to a subject, $s$, insofar as $s$ favours $o$ for $a$ 's sake.

\footnotetext{
${ }^{21}$ My analysis is not to be confused with what Rønnow-Rasmussen discusses under the rubric of 'De Facto Attitude Analysis of Personal Value' (DEFA) (2007: 414-416). DEFA is in fact very different from what I am proposing in this paper. On DEFA, an (actually held) attitude belonging to the person for whom something is good is always part of what makes this thing good for that person. Personal values are thus, according to DEFA, such that they always supervene in part on attitudes held by the person for whom they are valuable. RønnowRasmussen's example is of his daughter's poem, which, according to DEFA, would have personal value for him only if the value accrued to it in virtue of being favoured by him (in virtue of being an object of one of his proattitudes). That it is a necessary condition for something to be good for a person that it is favoured by the person for whom it is good is not an implication of the analysis that I propose. Indeed, my analysis is silent with regard to what personal values accrue to (and no attitude whatsoever need form part of the supervenience base of personal value). My analysis could actually be combined with DEFA, but I believe that we should reject DEFA on the same grounds that Rønnow-Rasmussen presents. (In a footnote, Rønnow-Rasmussen mentions a 'subjectivist version of DEFA', but this is still not identical to what I am proposing.)

${ }^{22}$ See, for example, Olson (2014) and Zimmerman (2009) for criticisms that primarily target the fittingness part of fitting-attitude analyses of personal value. However, both Olson and Zimmerman raise concerns about the forsomeone's-sake attitude itself, which are clearly relevant to my project.

${ }^{23}$ At least, it would change in the absence of whatever other factors that might hinder such a change.
} 
For example, if I am $s, a$ is Elisabeth, and $o$ is the event of Elisabeth winning the competition, then winning the competition is good for Elisabeth relative to me insofar as I favour for Elisabeth's sake that she wins the competition. Correspondingly, something would be bad for Elisabeth relative to me insofar as I disfavour it for her sake. It will be correctly observed that what is good for $a$ relative to $s$ may differ from what is good for $a$ relative to other subjects $s_{2}$ $s_{3}, s_{4}$, etc. each of whom may be favouring quite different things for $a$ 's sake. This might tempt a critic to ask 'but what then is good for $a$, really?' But insofar as this would be equivalent to asking what is objectively good for $a$, the subjectivist's answer is of course that nothing is. ${ }^{24}$ On the subjectivist's view, things are good or bad (relationally or non-relationally) only relative to the perspectives of individual subjects as determined by their attitudes. Once we move beyond particular first person perspectives and view the world from a third person perspective - from 'the point of view of the universe' - we will not see any values at all, either relational or non-relational. From that 'impersonal' perspective, nothing is good or bad, and neither is anything good or bad for anyone. This implication will no doubt be difficult for many to swallow, but those looking for a defence of value subjectivism in general or of its relativist implication will not find it in these pages. However, the proposed analysis of goodness for should, I believe, be attractive to those already within the subjectivist camp as it shows how the general subjectivist approach can be extended to cover the specific case of relational value and thereby show that subjectivists have the resources to handle relational values as well (or as badly) as they handle non-relational values.

\section{A Couple of Concerns and an Objection}

One potential concern regarding the analysis offered would be that it is not really an analysis of goodness for at all but only an analysis of goodness-for-relative-to. In order to dispel this worry, it is imperative to be clear on what belongs to the analysis and what belongs to the analysandum. What is being analysed is what it is for something to be good for someone, and this analysandum is supposed to be shared by everyone in the debate, including proponents of objectivist (and non-relativist) analyses of relational value. The subjectivist analysis offered above makes relational goodness relative to subjects' attitudinal perspectives, but the relativistic aspect comes in only at the philosophical level when we are trying, as value theorists, to understand the nature of goodness for. In no way does the analysis make the contents of our first order evaluations relative (either explicitly or implicitly so) or force ordinary evaluators to think or speak in relative terms. In everyday evaluative thought and discourse, what we think and say are things like ' $x$ is good' and ' $x$ is good for $a$ ' and not ' $x$ is good relative to me' or ' $x$ is good for $a$ relative to me'. As I have argued elsewhere (Fritzson 2016), 'relative to' is not meant to capture anything in our first order evaluative thought and discourse, but is instead a theoretical term used to express a certain second order idea about the relative nature of value.

Another concern is that by focusing on attitudes that are actually held, rather than attitudes that it would be fitting to have or that there are reasons to have, is not the subjectivist making values somehow arbitrary? This is a general concern about value subjectivism, and I will not

\footnotetext{
${ }^{24}$ As I have argued elsewhere (Fritzson 2016), 'good relative to' is not an inherently subjectivist notion, and an objectivist can be a relativist. Eric Mack (1993) is a case in point. He explicitly defends an objectivist form of value relativism. However, as I also argued in that 2016 paper, the subjectivist interpretation of 'good relative to', that fixes the relevant perspective with reference to the attitudes of the individual subject, is the best interpretation.
} 
be able to dispel this worry here. What I will do is to merely sketch one way in which a subjectivist can allow that some of our attitudes are misdirected and therefore disqualified from constituting value. Like subjectivist analyses of non-relational value, my analysis of goodness for could be subjected to a proviso requiring the subject to have an 'accurate picture' of the object. $^{25}$ That is, the favoured object, $o$, must really possess the features for which it is being favoured by $s$ (for $a$ 's sake) in order for $s$ 's pro-attitude to bestow any value (for $a$ ) on $o$; $o$ must really possess the properties that are good-for- $a$-making relative to $s$. If, for example, I wish for Elisabeth's sake that she wins the competition in virtue of it being the most prestigious competition in the game, but that it is nothing of the sort, then my attitude is, in that sense, misdirected and fails to bestow any value on Elisabeth winning this competition.

This might be a good place to elaborate on one aspect of value subjectivism that was left underspecified in the brief description given in Section 4. On one interpretation of this view, what is going on when a subject is having an attitude towards something is only loosely described by saying that value is being conferred upon an object (a value bearer). Strictly speaking, it is rather the status of being value-makers that is being conferred onto the features of the object for which it is being favoured. ${ }^{26}$ Hence, by favouring an object in virtue of some of its properties, $s$ bestows upon these properties the status of being value-makers relative to $s$. If, for example, $s$ favours $o$ on account of properties $P_{1}, \ldots, P_{n}$, this is taken to bestow upon $P_{1}, \ldots, P_{n}$ the status of being value-makers relative to $s .{ }^{27}$ If $o$ in fact lacks some or all of the properties for which it is being favoured, it is then not valuable relative to $s$ despite being the object of $s$ 's pro-attitude. This implication is less surprising than it might first appear, bearing in mind that values are supposed to supervene on those properties for which the object is being favoured; when the object does not actually possess these properties, the relevant supervenience base is thus absent, and there is nothing there for the value in question to supervene on. Another object, $o_{2}$, which might be wholly unknown to $s$, might however possess $P_{1}, \ldots, P_{n}$ in which case it is valuable relative to $s$ even though it has never been the direct object of any of $s$ 's attitudes. The consequence that things of which we are not aware might still be good relative to us might seem to invite a form of objectivism in disguise. But this is only seemingly so, as the defining subjectivist idea that values are created by attitudes is never abandoned. ${ }^{28}$

Transferring this reasoning to relational values and the previous example of Elisabeth winning the competition, this event, as you may recall, was favoured by me (for Elisabeth's sake) in virtue of being the most prestigious competition in the game, a feature that it (unbeknownst to me) did not actually possess. In this case, it is natural to conclude that despite being favoured by me for Elisabeth's sake, winning the competition is not good for

\footnotetext{
${ }^{25}$ I defended the compatibility of such a proviso with subjectivism in Fritzson 2014. Cf. Sobel (2009) from whom I have borrowed the phrase 'accurate picture'.

${ }^{26}$ This idea was first suggested to me by David Alm. In Fritzson 2014, I discuss this under the rubric of 'Alm's proposal'.

${ }^{27}$ However, we need not say that a property that is a value-maker in one context necessarily plays this role in every context. One and the same property or set of properties can be value-making in one context and at the same time not be value-making in another context. Whether a particular property or set of properties is value-making or not in a particular context may depend on the presence or absence of certain other features. A subjectivist may want to follow Jonathan Dancy (2004) in saying that features that are not themselves value-makers (such as enabling and disabling conditions) might make a difference to the value of an object.

${ }^{28}$ In Fritzson 2014, I introduced the terms 'direct' and 'indirect' value constitution to signify this distinction. (As pointed out to me by David Alm, this reasoning seems to presuppose an understanding of properties as universals.)
} 
Elisabeth relative to me because it lacks that in virtue of which I favour it for her sake. A totally different competition that is wholly unknown to me might however be the most prestigious one, in which case, winning this competition is good for Elisabeth relative to me even though it has never been the direct object of any of my attitudes.

Finally, an objection that has been raised against my analysis of good for is that we might want to say, in at least some cases, that an object that is being favoured for someone's sake is nonetheless not good for that someone. Imagine, for example, that you desire something for a deceased friend's sake. Might you not at the same time deny that this would be good for your friend? ${ }^{29}$ I will now explain why I do not find this objection convincing. The example trades on the intuition that nothing can be good or bad for someone who is no longer alive. I do not think that this is quite so obvious; at least, it is not something that can be excluded on the level of second order value theory. Imagine, for example, that what you wish for your dead friend's sake is that she is posthumously cleared of some false allegation made against her towards the end of her life, or alternatively that some goal that he was working towards for most of his life is finally being brought to fruition. In such cases, it is not implausible, I believe, to say that these things would be good for your friend even though he himself or she herself would not be around to appreciate them (of course, we may also wish for our friends' sakes that they would still be alive and be able to experience and witness such events, but then it is this that would be the object of our attitudes).

One reason, I believe, that many people have the intuition that nothing can be good or bad for someone who is no longer alive is that they have in mind (what I above called) the welfare sense of good for. As previously noted, while this is a legitimate sense of good for, it is not the only one, and my analysis is not restricted to the values picked out by this sense of good for. Though it may well be correct that it is not possible (and perhaps even fundamentally confused to want) to enhance the well-being of a deceased person, things other than their well-being may still be good for a dead person. What those other things might be can only be answered by taking a normative stance on what is good for people (something that I have avoided in this paper), but my examples above of being posthumously cleared of some false allegation, or having a lifelong project bear fruit after one's death, are plausible candidates. We might wish such things for a deceased person's sake even if we do not believe that it can enhance his or her well-being.

Leaving aside the special case of the dead, might there still be something to the objection that it is possible to favour something for someone's sake while at the same time plausibly denying that this thing is good for that someone? This remains to be shown, but a convincing counterexample of this sort would have to be such that it is clear that the attitude is really a for-someone's-sake attitude and not some other kind pro-attitude such as respect or honouring. One may well, for example, favour something in honour of someone without favouring it for that someone's sake.

\section{Concluding Note}

A distinctly subjectivist analysis of the nature of relational value, or of what it is for something to be good for someone, has been proposed. Like the generic subjectivist analysis of value, the proposal is to analyse value in terms of attitudes. The proposed analysis of goodness for appeals to a special kind of attitude: for-someone's-sake attitudes. Unlike other analyses in the literature that have appealed to for-someone's-sake attitudes, the analysis proposed here is not a fitting-attitude analysis. Rather than appealing to for-someone's-sake attitudes that it is fitting to have or that there are reasons to have, the

${ }^{29}$ This objection has been put to me in personal communication by Johan Brännmark. 
proposed analysis takes actually held for-someone's-sake attitudes to ground or constitute goodness for (relative to the subject who holds the attitude). This analysis should be attractive to those already within the subjectivist camp as it is an extension of the generic subjectivist view of value, thus showing that subjectivism provides the resources to analyse relational values.

Acknowledgements Earlier versions of this paper were presented at the Thumos seminar of the Swiss Centre for Affective Sciences in Geneva and at the Value Research Seminar of the Nova Institute of Philosophy in Lisbon. I wish to thank the people who attended and gave helpful comments on these occasions. I also wish to thank Toni Rønnow-Rasmussen who gave many helpful comments and suggestions. The research was funded by grants from the Swedish Research Council (2016-06692) and the Portuguese Foundation for Science and Technology (FCT) (Project reference: BPD-PTDC/MHC-FIL/0521/2014).

Open Access This article is distributed under the terms of the Creative Commons Attribution 4.0 International License (http:/creativecommons.org/licenses/by/4.0/), which permits unrestricted use, distribution, and reproduction in any medium, provided you give appropriate credit to the original author(s) and the source, provide a link to the Creative Commons license, and indicate if changes were made.

\section{References}

Dancy J (2004) Ethics without principles. Oxford University Press, Oxford

Fritzson F-A (2014) Value Grounded on Attitudes: Subjectivism in Value Theory (doctoral dissertation). MediaTryck, Lund

Fritzson F-A (2016) Good, good for, and good relative to: relative and relational in value theory. Philosophy 91: 255-267

Gauthier D (1986) Morals by agreement. Oxford University Press, Oxford

Hurka T (1987) 'Good' and 'good for'. Mind 96:71-73

Kagan S (1998) Rethinking intrinsic value. J Ethics 2:277-297

Korsgaard, Christine M. 2013. The relational nature of the good. In Oxford Studies in Metaethics (vol 8), ed Russ Shafer-Landau, 1-26. Oxford: Oxford University Press

Korsgaard CM (2014) On having a good. Philosophy 89:405-429

Kraut R (2011) Against Absolute Goodness. Oxford University Press, Oxford

Mack E (1993) Agent-relativity of value, deontic restraints, and self-ownership. In: Frey RG, Morris C (eds) Value, welfare, and morality. Cambridge University Press, Cambridge, pp 209-232

Moore, G.E. (1993/1903). Principia Ethica (revised ed.). Cambridge: Cambridge University Press

Olson J (2014) The personal and the fitting' (review article). J Moral Philos 11:341-352

Rabinowicz W, Österberg J (1996) Value based on preferences: on two interpretations of preference utilitarianism. Econ Philos 12:1-27

Rabinowicz W, Rønnow-Rasmussen T (2000) A Distinction in Value: Intrinsic and For Its Own Sake. Proceedings of the Aristotelian Society 100:33-51

Regan DH (2004) Why am I my Brother's keeper? In: Jay Wallace R, Pettit P, Scheffler S, Smith M (eds) Reason and value: themes from the moral philosophy of Joseph Raz. Clarendon Press, Oxford, pp 202-230

Rønnow-Rasmussen, Toni. 2003. Subjectivism and objectivism. In Patterns of value: Essays on formal axiology and value analysis (vol. 1), eds. Wlodek Rabinowicz and Toni Rønnow-Rasmussen. Lund philosophy reports 2003:1. Lund University

Rønnow-Rasmussen T (2007) Analysing Personal Value. J Ethics 11:405-435

Rønnow-Rasmussen T (2011) Personal Value. Oxford University Press, Oxford

Rosati CS (2006) Personal good. In: Metaethics after Moore, eds. Terry Horgan and mark Timmons. Oxford University Press, Oxford

Rosati CS (2008) Objectivism and relational good. Soc Philos Policy 25:314-349

Rosati CS (2009) Relational good and the multiplicity problem. Philos Issues 19:205-234

Smith M (2013) On the nature and significance of the distinction between thick and thin ethical concepts. In: Kirchin S (ed) Thick concepts. Oxford University Press, Oxford

Sobel D (2009) Subjectivism and idealization. Ethics 119:336-352

Thomson JJ (1997) The right and the good. J Philos 94:273-298

Zimmerman MJ (2001) The nature of intrinsic value. Rowman and Littlefield, London

Zimmerman MJ (2009) Understanding What's good for us. Ethical Theory Moral Pract 12:429-439 